\title{
Intermittent structural weakening and acceleration of the Thwaites Glacier Tongue between 2000 and 2018
}

\section{Paper}

Cite this article: Miles BWJ, Stokes CR, Jenkins A, Jordan JR, Jamieson SSR, Gudmundsson GH (2020). Intermittent structural weakening and acceleration of the Thwaites Glacier Tongue between 2000 and 2018. Journal of Glaciology 66(257), 485-495. https://doi.org/10.1017/jog.2020.20

Received: 24 July 2019

Revised: 3 March 2020

Accepted: 4 March 2020

First published online: 26 March 2020

\section{Key words:}

Antarctic glaciology; calving; ice shelves; ice velocity; ice/ocean interactions

\section{Author for correspondence:}

B. W. J. Miles,

E-mail: a.w.j.miles@durham.ac.uk
B. W. J. Miles ${ }^{1}$ (D) C. R. Stokes ${ }^{1}$, A. Jenkins ${ }^{2,3}$, J. R. Jordan², S. S. R. Jamieson ${ }^{1}$ and G. H. Gudmundsson ${ }^{2}$

${ }^{1}$ Department of Geography, Durham University, Durham, DH1 3LE, UK; ${ }^{2}$ Department of Geography and Environmental Sciences, Northumbria University, Newcastle upon Tyne, NE1 8ST, UK and ${ }^{3}$ British Antarctic Survey, Natural Environment Research Council, Cambridge, UK

\section{Abstract}

Evolving conditions at the terminus of Thwaites Glacier will be important in determining the rate of its future sea-level contribution over the coming decades. Here, we use remote-sensing observations to investigate recent changes (2000-2018) in the structure and velocity of Thwaites Glacier and its floating tongue. We show that the main trunk of Thwaites Glacier has accelerated by $38 \%$ over this period, while its previously intact floating tongue has transitioned to a weaker mélange of fractured icebergs bounded by sea ice. However, the rate of structural weakening and acceleration was not uniform across the observational period and we identify two periods of rapid acceleration and structural weakening (2006-2012; 2016-2018), separated by a period of deceleration and re-advance of the structurally-intact shear margin boundary (2012-2015). The timing of these accelerations/decelerations strongly suggests a link to variable ocean forcing. The weakened tongue now has some dependency on landfast sea ice for structural integrity and is vulnerable to changes in landfast ice persistency. Future reductions in landfast sea ice could manifest from changes in climate and/or the imminent removal of the B-22A iceberg from the Thwaites embayment. Such changes could have important implications for the integrity of the ice tongue and future glacier discharge.

\section{Introduction}

Observations have shown that the Amundsen Sea Sector of the West Antarctic Ice Sheet (WAIS) is currently losing mass at a greater rate than anywhere else in Antarctica (Shepherd and others, 2018; Rignot and others, 2019). Ice shelves in the region have been rapidly thinning (Paolo and others, 2015) and ice discharge has increased 77\% between 1973 and 2014 (Mouginot and others, 2014), resulting in inland thinning and grounding line (GL) retreat (McMillan and others, 2014; Konrad and others, 2018; Milillo and others, 2019). These changes are thought to be in response to periodic intrusions of warm-Circumpolar Deep Water that increase basal melt rates beneath ice shelves and ice tongue (Thoma and others, 2008; Jenkins and others, 2010, 2018).

While the present day mass loss of the Amundsen Sea Sector is of significant concern, there is a potential for a much higher rate of mass loss in the near-future (Golledge and others, 2015; DeConto and Pollard, 2016). Of particular concern is the Thwaites Glacier Catchment, which holds enough ice to raise global mean sea level by $59 \mathrm{~cm}$ (Holt and others, 2006) and, together with adjacent catchments, the WAIS holds enough ice to raise global mean sea level by more than $3 \mathrm{~m}$ (Scambos and others, 2017). As most of the ice in the Thwaites catchment is grounded on bedrock that lies below sea level and that deepens inland (Fretwell and others, 2013), there is potential for marine ice sheet instability to accelerate mass loss beyond that which might be expected from external forcing alone (Mercer, 1978; Schoof, 2007), unless ice shelves provide a sufficient amount of butressing (e.g. Gudmundsson and others, 2012; Gudmundsson, 2013; Gudmundsson and others, 2019). Indeed, some numerical models (Joughin and others, 2014; Seroussi and others, 2017) and observations (Rignot and others, 2014) have raised the possibility that the early-onset of this irreversible process may already be underway in the Thwaites Basin. If floating ice shelves are lost at some point during this process, resulting in the formation of unstable ice cliffs, there is potential for much higher rates of mass loss (DeConto and Pollard, 2016). However, at present, there are very few observations to constrain this process and it may not be required to explain past changes in sea level from Antarctic ice loss (Edwards and others, 2019).

Given the above, it is clear that the evolving conditions at the ice front of Thwaites Glacier are likely to be an important control on the rates and timing of future sea level contributions (e.g. Scambos and others, 2017). In this paper, we use satellite imagery to investigate the changes in structure of the Thwaites Glacier Tongue over the past 18 years (2000 to 2018). We analyse how the observed changes in structure relate to changes in both its calving pattern and its velocity, and then discuss the observed changes in relation to the near-future evolution of Thwaites Glacier. 


\section{Data and methods}

\subsection{Ice-front positions 2000-2018: MODIS}

We measured annual changes in the ice front position and velocity of Thwaites Glacier, extending the observations from MacGregor and others (2012), which spanned the period 1972 to 2011. We digitised ice front positions using MODIS imagery, obtained from the NASA WorldView application, and acquired every March from 2000 to 2018 (Dataset S1). In some cases, the heavily fractured nature of the Thwaites Glacier Tongue made mapping the ice front difficult. For consistency, we took the same approach for each image and always mapped the outer edge of connected ice blocks at each time step (Fig. S1). Changes in the ice front position were quantified using the box method, which takes into account uneven changes along the ice front (Moon and Joughin, 2008; Miles and others, 2016).

\subsection{Annual velocity fields (2000-2017)}

Velocity fields from 2000 and 2002 were obtained from Mouginot and others (2014). These datasets were processed using Radarsat- 1 data from the austral winter and are available at a spatial resolution of $450 \mathrm{~m}$, with errors of $\pm 5 \mathrm{~m} \mathrm{a}^{-1}$ (Mouginot and others, 2014). Annual velocity fields between 2005-2006 and 2016-2017 were obtained from the MEaSUREs dataset (Mouginot and others, 2017). These products are derived from the stacking of multiple velocity fields derived from a variety of sensors between July and June in the following year, and are available at $1 \mathrm{~km}$ spatial resolution. Errors in these products are estimated by a combination of the std dev. and count of scenes and vary from year to year (Mouginot and others, 2017). For simplicity we assume the error to be the largest error estimate $\left( \pm 32 \mathrm{~m} \mathrm{a}^{-1}\right)$ for all years.

\subsection{Sub-annual velocity fields (2013-2018): Landsat-8 and Sentinel-1}

In addition to the annual velocity datasets described above, we also used Landsat- 8 and Sentinel- 1 satellites for ice velocity measurements at a higher temporal resolution (16 and 6/12 d, respectively). We used the pre-computed raw Landsat-8-derived velocity fields available from the GoLive dataset (Fahnestock and others, 2016), that are available at a $600 \mathrm{~m}$ spatial resolution from November 2013 onwards. To maximise temporal coverage, we used all six Landsat-8 scenes which cover Thwaites Glacier and include all velocity fields generated from image pairs separated by 16,32 and $48 \mathrm{~d}$ (Dataset $\mathrm{S} 1$ ). The raw velocity fields were postprocessed to improve their overall quality. This was done by removing pixels that had the following properties: (i) peak correlation values below a threshold of the normalised cross-correlation algorithm from the GoLive workflow of less than 0.3 or (ii) values outside the range of $\pm 50 \%$ of the MEaSUREs velocity product. Once these pixels were removed, the final velocity product was computed by applying a $3 \times 3$ low-pass filter.

For Sentinel-1 data we used an automated workflow from the European Space Agency Sentinel Application Platform (SNAP) to compute velocity fields. We first download Interferometric Wide Swath (IW) Ground Range Detected (GRD) images from the Copernicus Sentinel Hub before applying precise orbits and calibration. These images have been consistently available over Thwaites since late 2015 (Dataset S1). Pairs of images on the same orbit path, separated by either 6 or $12 \mathrm{~d}$, are then co-registered using precise orbits. We use the SNAP offset tracking algorithm to produce initial velocity fields using a window of $128 \times 128$ pixels, before projecting it onto a WGS 84 grid at a pixel spacing of $300 \mathrm{~m}$. Erroneous pixels were then removed if the difference from the MEaSUREs velocity product was greater than $\pm 50 \%$, before a $3 \times 3$ low-pass filter was applied. Similarly high temporal resolution velocity time series have been presented from Greenland using Sentinel-1 data (Lemos and others, 2018). We also use Sentinel-1 imagery to map changes in ice front position every 2 months between January 2014 and August 2018.

To produce a time series of changes in ice speed between 2000 and 2017, we extracted mean ice speed from a $\sim 50 \mathrm{~km}^{2}$ box over the 2011 GL (Fig. 1) obtained from the MEaSUREs dataset (Rignot and others, 2011b). In each epoch there were no missing pixels within the defined box. To produce further high temporal resolution time series of ice speed between November 2013 and August 2018, and establish the spatial pattern of any change, we also extracted mean ice speed from three $50 \mathrm{~km}^{2}$ boxes further down-ice on the floating ice tongue (see Fig. 1). These include two locations in the shear zone between the Thwaites Glacier Tongue and its Eastern Ice Shelf (referred to as the Northern Shear Zone (NSZ) and the Southern Shear Zone (SSZ)) and on the Thwaites Eastern Ice Shelf (TEIS). Because the relative changes in the speed of the shear zone and Eastern Ice Shelf (at NSZ, SSZ and TEIS) were much greater, we used the raw velocity fields i.e. without removing pixels greater than $\pm 50 \%$ of the MEaSUREs dataset. To account for any bias arising from missing pixels, we only include time steps where at least $95 \%$ of pixels are present within each box.

To estimate the relative error (precision) in our high temporal resolution time series of ice speed we first calculated the difference in ice speed between each successive point in the time series at each location (e.g. TEIS, NSZ, SSZ and GL). The difference between each successive point represents the sum of the relative error and the trend or absolute change in speed between the two image pairs. To isolate the relative error we then subtracted the trend in the ice speed change at each point, which we take as the moving average of the previous 10 points in the time series. This produces median relative errors of $\pm 0.22,0.18,0.17$ and $0.07 \mathrm{~m} \mathrm{~d}^{-1}( \pm 80,66,62$ and $26 \mathrm{~m} \mathrm{a}^{-1}$ ) for TEIS, NSZ, SSZ and GL, respectively. Some individual points have considerably higher relative errors, as reflected by the $90^{\text {th }}$ percentiles of $\pm 0.78,0.59,0.57$ and $0.16 \mathrm{~m} \mathrm{~d}^{-1}( \pm 284,215$, 208 and $58 \mathrm{~m} \mathrm{a}^{-1}$ ), respectively. To account for these errors when comparing ice speeds at different time periods (e.g. difference between December 2015 and June 2018) we take a median of 10 consecutive velocity fields and assume a reasonable error to be the median relative error stated above.

\section{Results}

\subsection{Annual observations (2000-2018)}

Our ice front data show that in 2000, Thwaites Glacier extended $\sim 120 \mathrm{~km}$ seaward as an intact and coherent floating ice tongue (Fig. 2a). Since then, there have been significant changes to both its extent and structural integrity. Initially, in March 2002, the calving of a $3400 \mathrm{~km}^{2}$ tabular iceberg resulted in $\sim 75 \mathrm{~km}$ of ice front retreat, before a re-advance occurred (Figs $2 \mathrm{a}$ and $3 \mathrm{a}$ ). Between 2006 and 2012 we observed the development of major rifting and fractures on the ice tongue $\sim 20$ and $35 \mathrm{~km}$ downstream of the GL and in the shear zone with the TEIS (Figs 2b-e), but not further downstream near the ice front. In 2012 , another major tabular calving event resulted in the retreat of the ice front $80 \mathrm{~km}$ behind its position in 2000 (see 2013 position on Figs $2 \mathrm{a}$ and $3 \mathrm{a}$ ). The 2012 calving event also marked the complete transition of the Thwaites Glacier Tongue from a largely intact ice tongue capable of the production of large tabular icebergs, to a mélange of fractured icebergs ranging from $\sim 1-5 \mathrm{~km}$ in width and bound together by sea ice (Figs $2 \mathrm{f}-\mathrm{j}$ ). The exception to this was at the ice front, where a $\sim 470 \mathrm{~km}^{2}$ iceberg remained fastened to the ice front, a relic of the 2012 calving event 


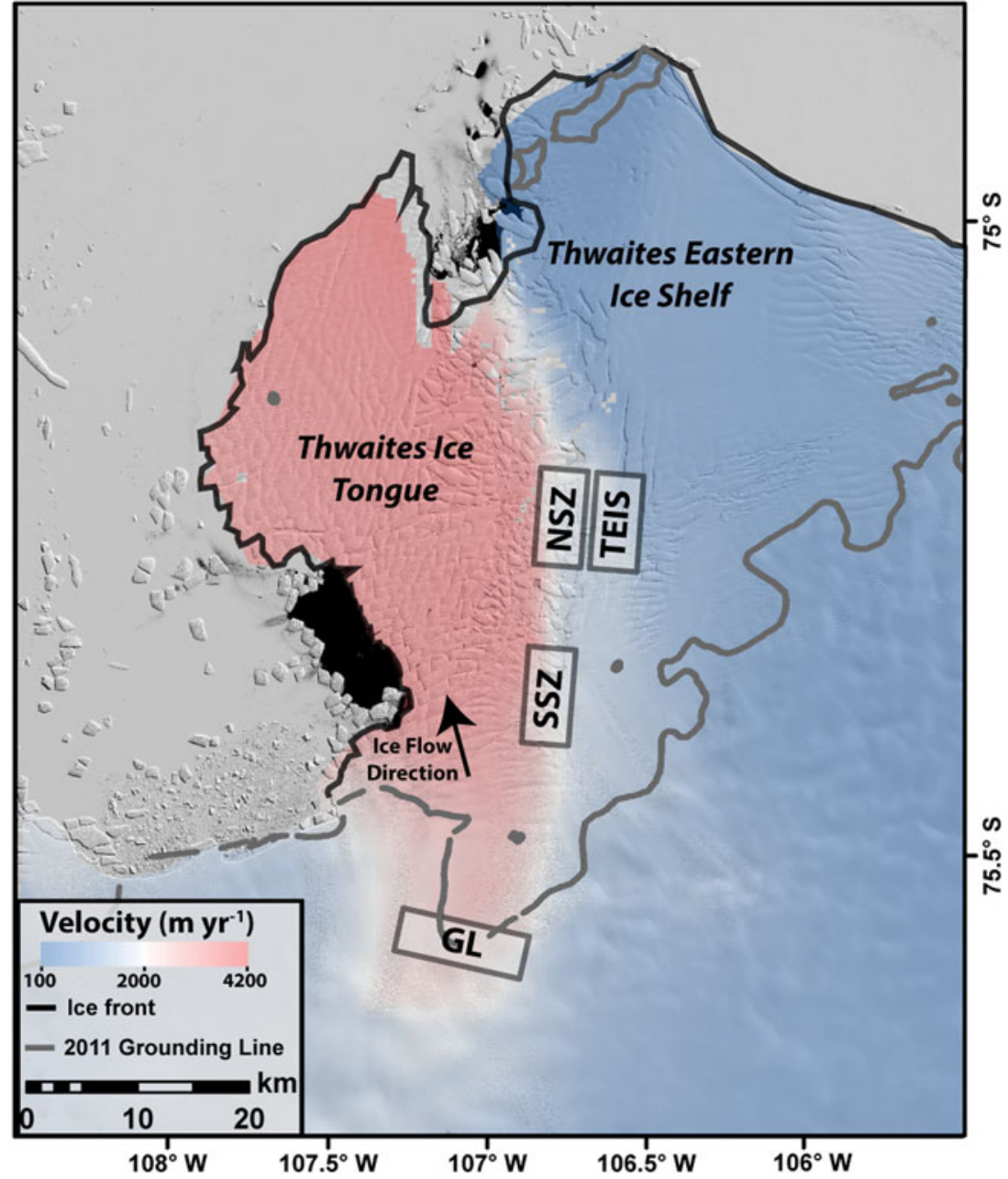

Fig. 1. Landsat-8 image from November 2013 of the Thwaites Ice Tongue and Eastern Ice Shelf, overlain with the MEaSUREs 2011 GL (Rignot and others, 2011a) and the MEaSUREs composite velocity product (Rignot and others, 2011b). The boxes where our velocity time series are extracted as spatial averages: NSZ, SSZ, TEIS and GL. Note the steep velocity gradient between the Thwaites Ice Tongue and Eastern Ice Shelf.
(Figs 2f, k). Until January 2016, this iceberg was coalescent with the main Thwaites Tongue via dense ice mélange, which has known mechanical integrity (Rignot and MacAyeal, 1998). Between January and April 2016 it began to disintegrate.

Overall, annual speed at the GL (averaged from box GL) increased 38\% between 2000-2001 and 2016-2017 (from 1957 \pm 5 to $2696 \pm 32 \mathrm{~m} \mathrm{a}^{-1}$ ). We note that there was little change in ice speed following the $\sim 75 \mathrm{~km}$ retreat of its ice front in 2002 (Figs 3a, b). Most of the overall acceleration during the observation period took place between 2005-06 and 2011-12, where ice speed increased rapidly from $2072 \pm 32$ to $2560 \pm 32 \mathrm{~m} \mathrm{a}^{-1}$ (Fig 3b). During this period of rapid acceleration there were no significant calving events and the ice front steadily advanced (Fig. 3a). Thus, the period of rapid acceleration (Fig. 3b) coincides more generally with the onset of the structural weakening of the Thwaites Glacier Tongue between 2006 and 2012 (Fig. 2). From 2012-13 until 2015-16, there was a 6\% slowdown in ice speed and the ice front advanced (Fig. 3b). The largest annual increase in ice speed occurred between 2015-16 and 2016-17 where ice speed increased from $2530 \pm 32$ to $2696 \pm 32 \mathrm{~m} \mathrm{a}^{-1}$ (Fig. 3b). Similar patterns in ice speed between 2000 and 2018 were present upstream of box GL, demonstrating that these changes in ice speed have not been caused by any ungrounding of ice in the vicinity of box GL, and are representative of wider changes in the system.

\subsection{High temporal resolution observations November 2013- August 2018}

The high temporal resolution time series from Landsat- 8 and Sentinel-1 (Fig. 4) shows substantial variability in glacier flow rates. Between November 2013 and December 2015 we observed a $9 \mathrm{~km}$ ice front advance (Fig. $4 \mathrm{e}$ ) and there was little change in ice speed at the GL; however, ice speed decreased along the eastern shear margin, by $22 \%$ in the NSZ (Fig. 4 b) and $10 \%$ in the SSZ (Fig. 4c). In contrast, ice on the TEIS (Fig. 4a) accelerated by 27\% between November 2013 and December 2015. During this time period we observed no further structural weakening of the Ice Tongue and observed an advance of the structurally intact boundary between the Thwaites Ice Tongue and the Eastern Ice Shelf (Fig. 5), indicating a strengthening of the shear margins.

There was a notable change in glacier behaviour in early 2016, when the velocity patterns across Thwaites Glacier switched: between January 2016 and March 2017, ice flow at the GL steadily accelerated by $7 \%$ (GL; Fig. 4d). This coincided with a rapid change in behaviour of ice in the eastern shear zone where, between January and May 2016, the NSZ accelerated by $75 \%$ (NSZ; Fig. 4b). Simultaneously, ice at the TEIS accelerated by $57 \%$ (TEIS; Fig. $4 \mathrm{a}$ ) over the 5 month period. While the nearinstantaneous acceleration at the NSZ was maintained up to the end of the observational period, ice speed at the TEIS decreased by $60 \%$ between June 2016 and August 2018 (TEIS; 4a). This included a near-instantaneous decrease in ice speed of $40 \%$ between June 2016 and September 2016 (Fig. 4a). By August 2018, ice speed in the SSZ had increased by 68\% (SSZ; Fig. 4c). The magnitude of this increase in ice speed is comparable to that of the NSZ, but unlike the abrupt increase there, the acceleration at the SSZ was more gradual (Fig. 4c). Coinciding with this speed-up, extensive rifts developed in the SSZ and, by October 2018, these had propagated to within a few kilometres of the 

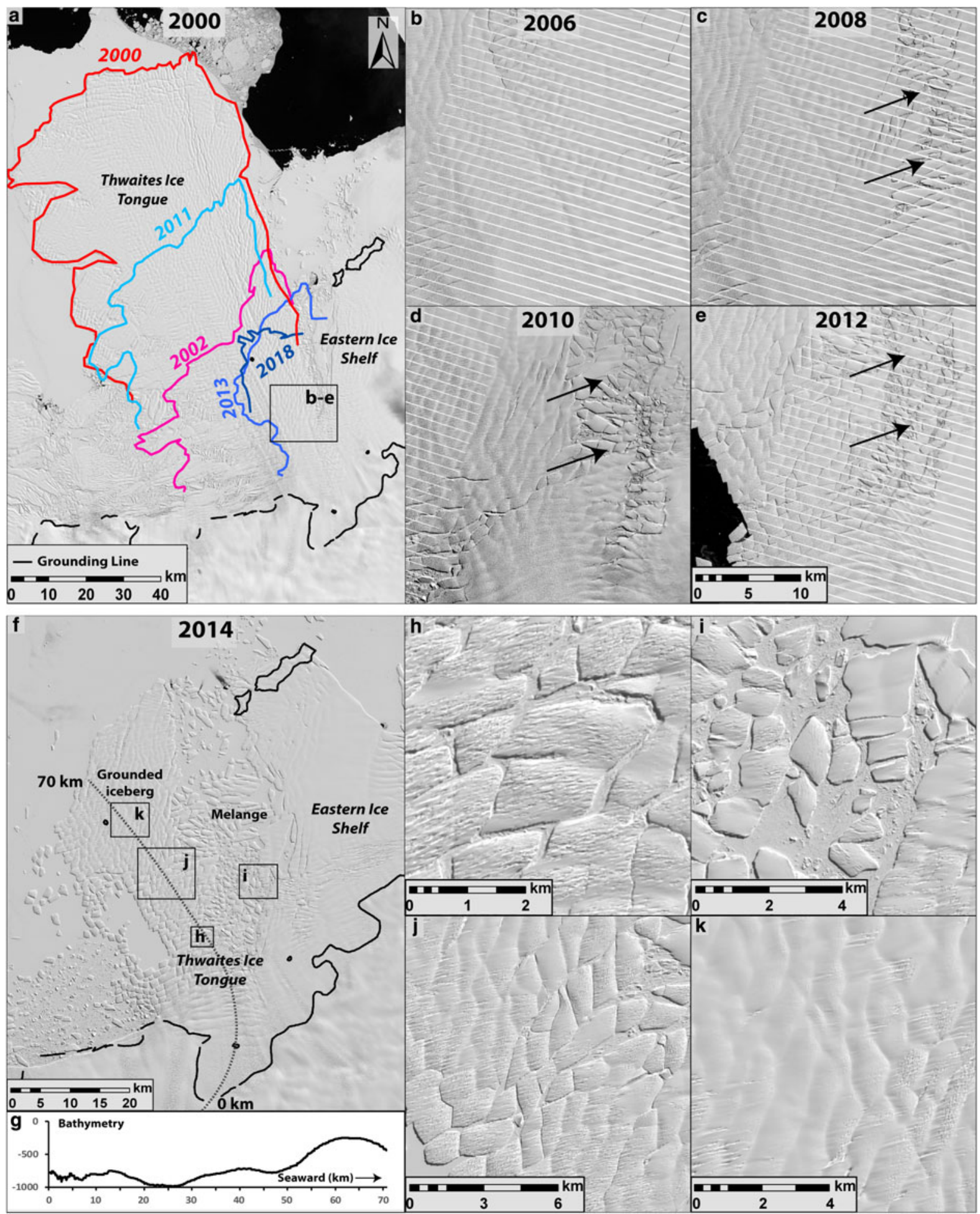

Fig. 2. Structural transition of the Thwaites Glacier Tongue. (a) Landsat- 7 image of the $120 \mathrm{~km}$ long Thwaites Glacier Tongue in 2000 with digitised ice front positions. The GL is from the MEaSUREs dataset in 2011 (Rignot and others, 2011a). (b-e) Landsat-7 images showing the changes in the structure of the Thwaites Glacier Tongue. The black arrows point to the development of rifts in each successive image. The location of these images is shown by the black boxes in a. (f) Landsat-8 image in 2014 weakened ice tongue. Note the structurally intact grounded iceberg. (g) Bathymetry (Millan and others, 2017) taken along the transect shown in $f$ (dotted line). Note the presence of the offshore ridge. (h-k) Close-ups of the Thwaites Glacier Tongue from 2014, the location of each image is shown in black boxes in $\mathrm{f}$.

GL (Fig. 5). Comparing the spatial pattern of velocity change both before (Nov 2013-Dec 2015) and after (June 2016-Aug 2018) January 2016, the largest velocity increase occurred along the eastern shear margin (Fig. 4f).

Between January 2016 and August 2018 the ice front retreated by $16 \mathrm{~km}$ (Fig. 4e). This period coincides with the break-up of the large iceberg fastened to the ice front between January 2016 and April 2016 (Fig. 6a). Notably, the break-up of this iceberg coincides with the onset of the acceleration across the ice tongue (Figs 4b, c). A second large calving event took place in February 2017 (Fig. 6b) but, there were no coincident changes in velocity on the Thwaites Glacier Tongue. 

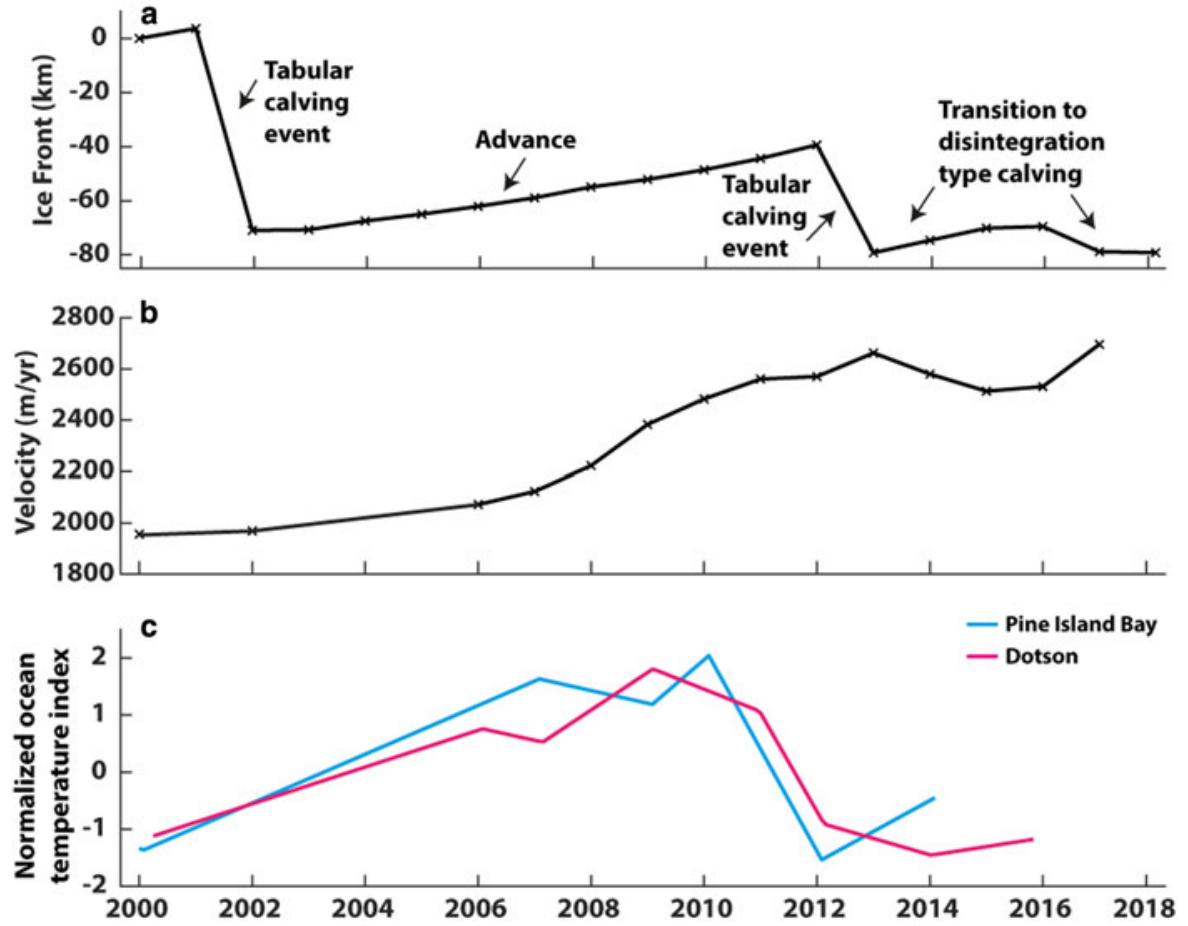

Fig. 3. Annual ice front (a) and velocity (b) changes 2000 and 2018. (c) Normalised ocean temperature index from Pine Island Bay (blue line; Jenkins and others, 2016) and Dotson (cyan line; Jenkins and others, 2018). Note the switch to cooler conditions in 2012.

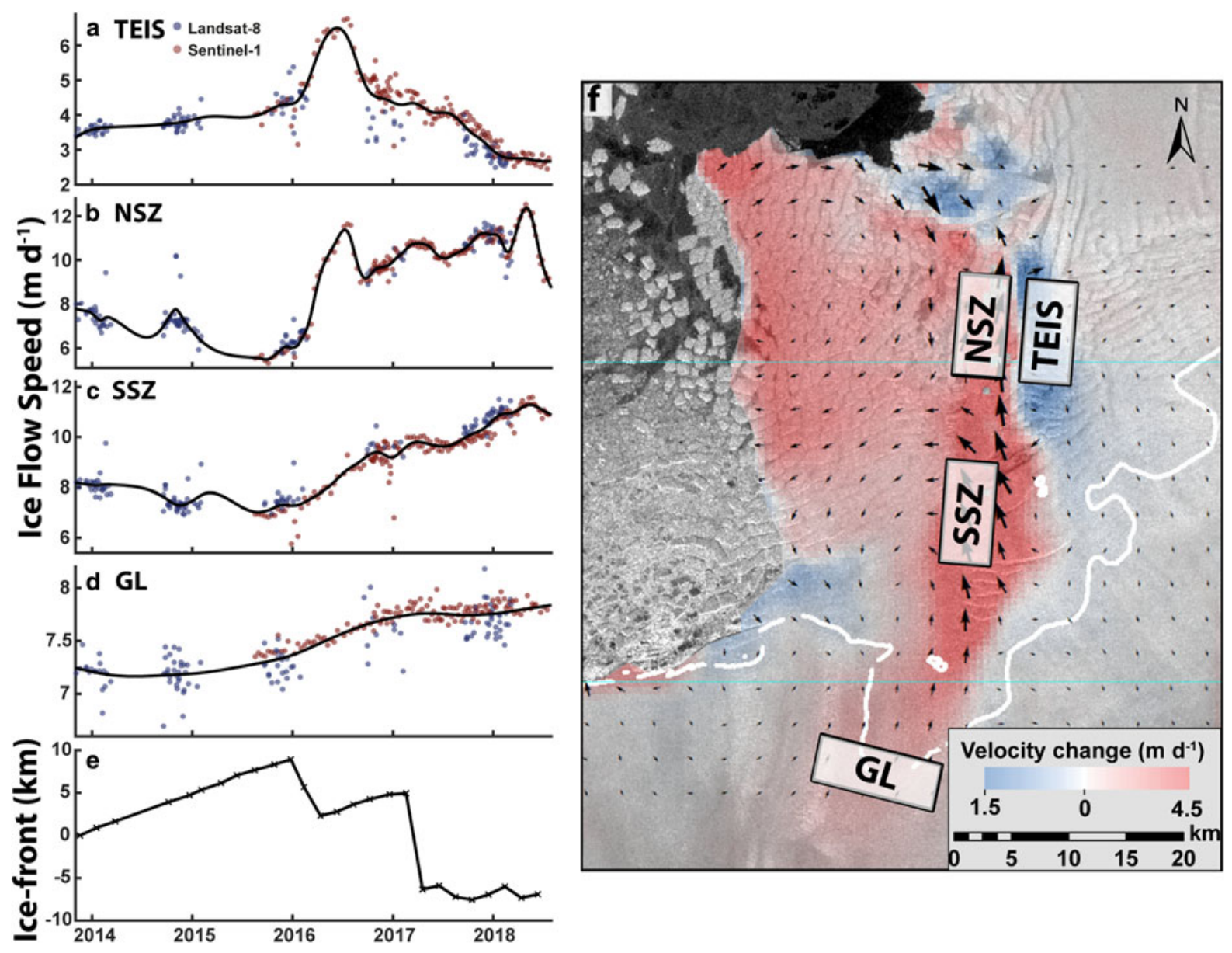

Fig. 4. High temporal resolution ice speed and ice front position changes between November 2013 and August 2018. (a) TEIS, (b) NSZ, (c) SSZ and (d) GL. The black line in each velocity panel is a smoothing spline. (e) Changes in the ice front position. (f) Difference in median velocity before January 2016 (Nov 2013-Dec 2015) and after (June 2016-Aug 2018) overlain on a Sentinel-1 image from August 2018, with red indicating a velocity increase and blue a decrease. Note the largest increases in velocity occur in the eastern shear zone. 


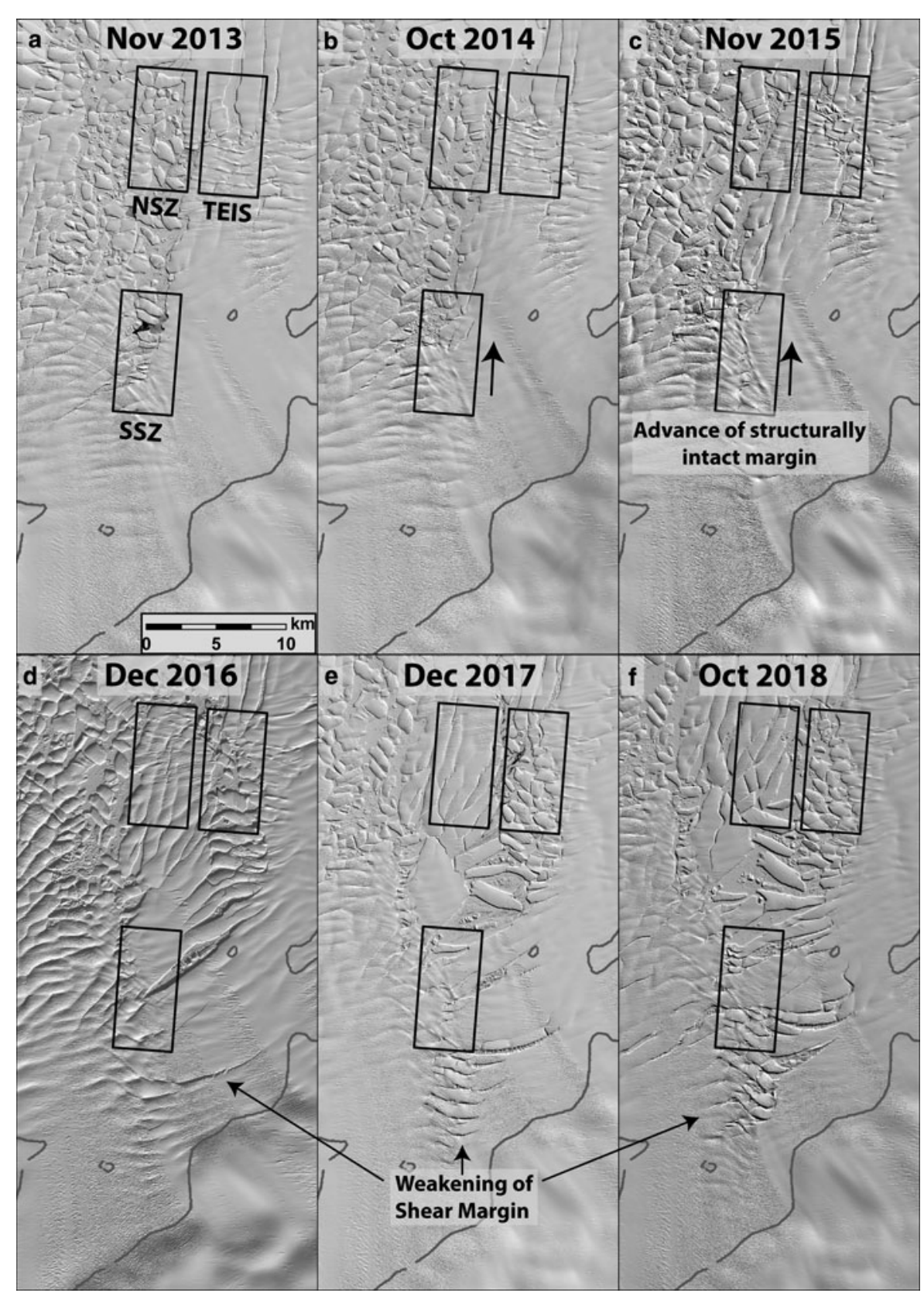

Fig. 5. Landsat 8 images from 2013 to 2018 showing the structural changes at the shear margin between the Thwaites Ice Tongue and Eastern Ice Shelf. From 2013 to $2015(a-c)$, there are no signs of further structura weakening and the structurally intact boundary between the ice tongue and Eastern Ice Shelf advances. From 2016 to 2018 (d-f) there is extensive structural weakening of the shear margin. The grey line is the 2011 GL (Rignot and others, 2011a).

\section{Discussion}

As reported in previous studies (MacGregor and others, 2012), there was no significant change in the speed of Thwaites Glacier following the $75 \mathrm{~km}$ retreat of its ice front as a result of the 2002 calving event (Figs 3a, b), which confirms that the calved ice was 'passive' and did not exert a significant buttressing effect (cf. Furst and others, 2016). This lack of response in ice speed is consistent with theoretical explanations for an unconfined ice shelf (Sanderson, 1979). Indeed, longer-term observations show that there was no significant change in the speed of Thwaites Glacier between 1992 and 2005 (MacGregor and others, 2012; Mouginot and others, 2014). However, ice speed increased by $24 \%$ between 2006 and 2012, which coincides with the onset of the structural weakening and transition to mélange of the Thwaites Glacier Tongue and eastern shear zone (Figs 2,3). Because shearing along the eastern margin of the Thwaites Glacier Tongue generates a stress that resists glacier flow (e.g. Rignot and others, 2006), any structural weakening of the ice tongue could create a positive feedback whereby structural weakening and accelerations reinforce each other (e.g. MacGregor and others, 2012). It has been hypothesised that this process could create a continuous process leading to further weakening of the shear margins until all resistance to ice shelf flow is lost (MacGregor and others, 2012).

Despite the major structural weakening and acceleration of Thwaites Glacier during the mid-2000s, it is clear that this has not been a continuous process. Between 2012 and 2015 ice speed on the main trunk of Thwaites Glacier decreased by $6 \%$ and there were no obvious signs of further structural weakening (Figs 3, 5). However, 2016 marks the beginning of another period of acceleration, structural weakening (Fig. 5), ice front retreat (Fig. 4) and, indeed, GL retreat (Milillo and others, 2019). We now consider the extent to which these periods of structural weakening may have been triggered by an external forcing (section 4.1), and we then examine the specific processes at play during the observed periods of change: the 2012-2015 slowdown (section 4.2) and the 2016 acceleration (section 4.3). We then explore the implications of the observed structural weakening on the interaction between the Thwaites Ice Tongue and landfast sea ice (section 4.4). 

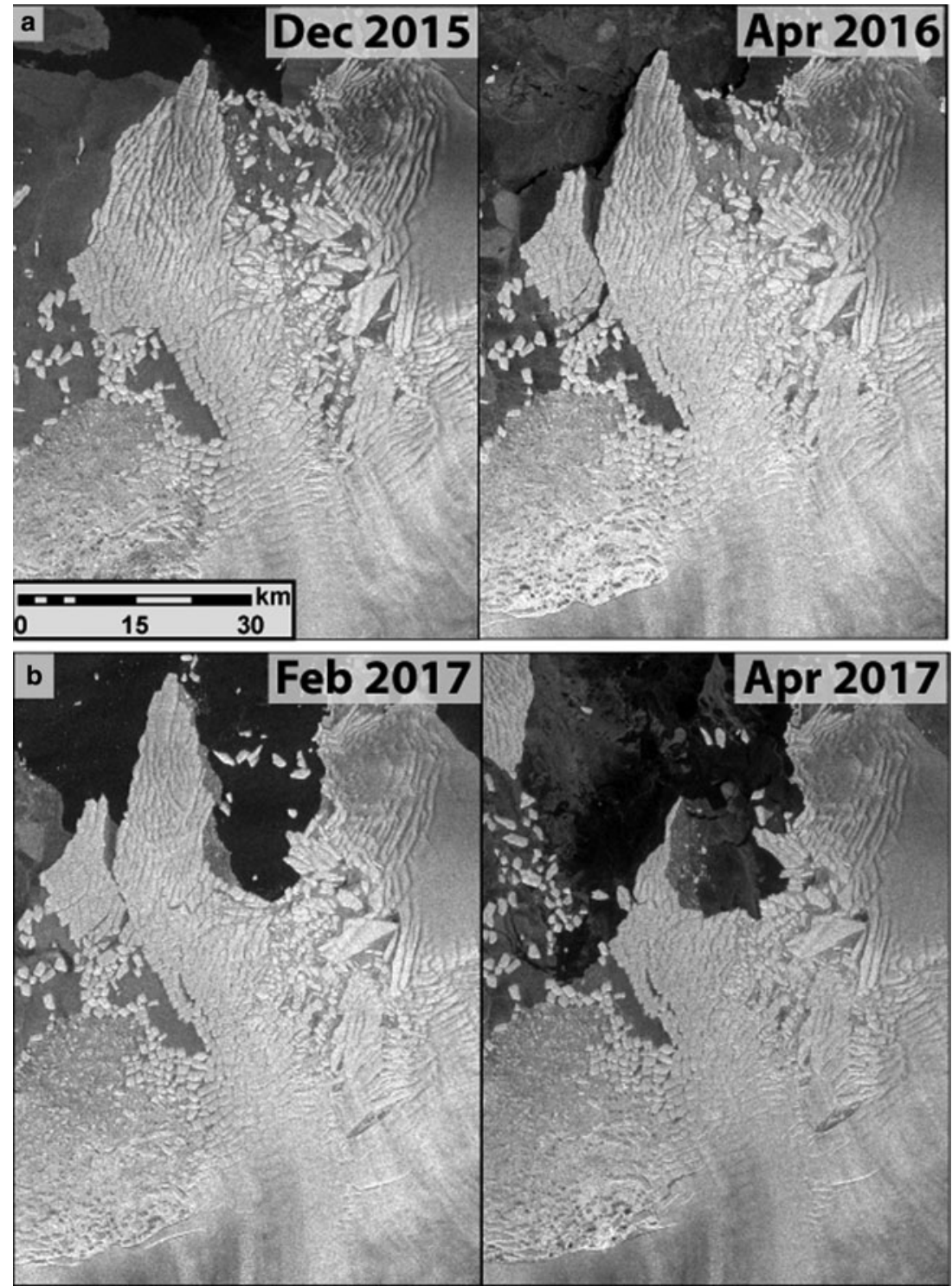

Fig. 6. Sentinel-1 IW GRD images of the (a) December 2015-April 2016 calving event. (b) February-April 2017 calving event.

\subsection{Ocean temperature variability as a control on structural weakening of the Thwaites Glacier Tongue}

Throughout the $20^{\text {th }}$ and $21^{\text {st }}$ centuries, oceanic conditions in the Amundsen Sea switched between periods of relative cool and extreme warmth (Jenkins and others, 2016, 2018). The onset of the structural weakening of the Thwaites Glacier Tongue coincided with a period of extremely warm oceanic conditions from the mid-2000s until the early 2010s, while the period of deceleration in the early 2010 s coincides with cooler conditions (Fig. 3c). This hints that ocean variability could be triggering the intermittent behaviour of Thwaites Glacier. Typically, such ocean variability is associated with changes at intermediate depth, at $\sim 300-700 \mathrm{~m}$ (e.g. Jacobs and others, 2013; Dutrieux and others, 2014; Jenkins and others, 2018), which is well below the ice tongue/mélange. However, increased melting in the vicinity of the GL could lead to the ungrounding of ice, reducing buttressing and subsequent acceleration of ice shelf flow, leading to a weakening of shear margins. Greater melting at depth and the associated shallower thermocline would also lead to more upwelling of warm water to the surface layers (Dutrieux and others, 2014), which could also directly weaken the ice shelf, mélange and shear margins, leading to further acceleration and ice front retreat. A combination of both these processes could explain the link between ocean variability and the timing of the accelerations and structural weakening of Thwaites Glacier. In contrast, under relatively cool conditions, lower melt rates could slowdown GL retreat and reduce melting of the ice tongue leading to a re-advance of the structurally intact shear margin boundary. In the following sections we discuss the importance of these physical mechanisms in the slowdown (2012-2015) and acceleration (2016-2018) of Thwaites Glacier using results from our high temporal resolution time series.

\subsection{Slow-down of Thwaites Glacier between 2012 and 2015}

The slow-down of the main Thwaites Glacier Tongue between 2012 and 2015 could only be explained by a re-grounding of ice and thickening, or a strengthening of the shear margins. There is no reported evidence of the former (e.g. Milillo and others, 2019), but our results show that the margin between the Thwaites Glacier Tongue and the TEIS strengthened over this time period. Between November 2013 and December 2015 the boundary of structurally intact ice between the Thwaites Glacier Tongue and Eastern Ice Shelf advanced by $6 \mathrm{~km}$ (Figs $5 \mathrm{a}-\mathrm{c}$ ), indicating a partial strengthening of the shear margin. Consistent with this strengthening is the reduction in velocity gradient between the faster flowing Thwaites Glacier Tongue and the slower flowing TEIS over the same time period (NSZ and TEIS; Figs 4a, b). 
Specifically, this is shown by a $22 \%$ reduction in ice speed at the faster flowing Thwaites Glacier Tongue (NSZ; Fig. 4b) and a $27 \%$ increase in ice speed at the slower flowing TEIS (Fig. 4a). This section of the TEIS (e.g. box TEIS) had been accelerating since 2008 (Mouginot and others, 2014), which was attributed to a partial ungrounding of a pinning point near the TEIS ice front (Tinto and Bell, 2011; MacGregor and others, 2012) or retreat of its GL (Rignot and others, 2014). While these processes may be contributing to some of the longer-term acceleration, the pattern of velocity observed in our results (Figs $4 \mathrm{a}, \mathrm{b}$ ) between November 2013 and December 2015 is entirely consistent with a partial recoupling in flow between the Thwaites Glacier Tongue and Eastern Ice Shelf between November 2013 and December 2015. This is where the faster flowing and more dominant Thwaites Glacier Tongue entrains the slower TEIS, resulting in its acceleration. Simultaneously, the greater shear stresses associated with a stronger shear margin results in a slowdown in velocity of the Thwaites Glacier Tongue.

While our results suggest that the strengthening of shear margins is likely to have been important in the slowdown of the Thwaites Glacier, other factors may also have contributed to the slowdown. One possibility is that the ice tongue may have re-grounded onto a pinning point or increased in a grounded area. Based on the 2011 GL (Rignot and others, 2011a), the ice tongue was likely stabilised by at least three small pinning points (Fig. 1). It is possible that small changes in the ice tongue thickness could have increased the grounded area and contributed to the slowdown. However, this is difficult to assess because no additional GL observations are available over this time period.

\subsection{January 2016 acceleration}

January 2016 marks the onset of a period of acceleration across the GL, weakening of the shear margins and a retreat of both the GL (e.g. Milillo and others, 2019) and ice front. The most rapid changes in ice speed occurred at the NSZ and at the TEIS, where in January 2016 ice speed increased by 75 and $57 \%$, respectively, over the course of a few weeks (Figs $4 a, b$ ). This resulted in a rapid steepening of the velocity gradient between the Thwaites Glacier Tongue and the TEIS, which ultimately led to further structural damage and a decoupling in flow between the two ice shelves. Consistent with this is the rapid 60\% deceleration of TEIS from August 2017 to February 2018 (Fig. 4a), associated with a reduction in shear from the faster flowing ice tongue. This pattern of velocity change is very similar to that reported by Mouginot and others (2014) at the onset of Thwaites Glacier's last major acceleration event in 2006. Thus, following the reported decoupling in flow between the two ice shelves in 2006, ice flow has since partially recoupled between 2013 and 2015, before decoupling again in 2016.

The acceleration of ice in the SSZ (Fig. 4c) in January 2016 was at a comparatively slower rate than ice in the NSZ (Fig. 4b), creating a steep velocity gradient. Over the following months, the increased longitudinal stresses associated with the steep velocity gradient (e.g. Benn and others, 2007) resulted in the development of a series of rifts along the eastern shear zone and to within a few kilometres of the GL (Fig. 5). The loss of buttressing associated with the weakening of the shear zone, may have played an important role in the increase in ice speed observed at the GL (e.g. Fig. 4d). Consistent with this is the spatial pattern of velocity change, which indicates that the largest increases in velocity are concentrated along the entire eastern margin (Fig. 4f).

The mechanism responsible for the initial increase in ice speed towards the ice front at the NSZ (Fig. 4b), in January 2016, is unclear. One possibility is that the rapid increase in speed at NSZ was a direct consequence of the break-up and calving of the large structurally intact iceberg fastened to the ice front (Fig. 6a). This iceberg may have been acting as an obstacle, helping to pin the mélange in the shear zone, meaning the break-up of the iceberg resulted in a near-instantaneous loss of buttressing in the NSZ. Consistent with this is the near-instantaneous acceleration of ice at NSZ (Fig. 4b), which observations elsewhere have shown to be a typical response to calving events which reduce buttressing (e.g. Scambos and others, 2004). In addition, the mélange at in the NSZ may have been weakened through a combination of enhanced ocean melt, the seasonal retreat of landfast sea ice and by surface melt. Indeed, it is notable that in January 2016 an anomalously large amount of surface melt was produced in the Thwaites embayment (Nicolas and others, 2017). An alternative explanation is that the acceleration at the NSZ could be linked to a rapid GL retreat which occurred over a similar time period to the observed acceleration (Milillo and others, 2019), or ungrounding of any pinning points. However, this seems unlikely because the acceleration of the NSZ occurred before any large increases in speed upstream either at the SSZ or at the GL (Figs 4a-d), which would be expected if GL retreat was the driver. Rather, after the initial weakening of the shear margins, GL retreat may have accelerated the inland propagation of structural weakening of the eastern shear margin. Regardless of the physical mechanism responsible for the initial increase in ice speed at NSZ, our results show that despite extensive structural weakening of the Thwaites Glacier Tongue, processes originating in the shear zone towards the ice front between the Thwaites Glacier Tongue and Eastern Ice shelf are still playing an important role in ice dynamics towards the GL. This highlights the importance in understanding the mechanisms which may lead to future changes in the stability of the ice tongue in the future.

\subsection{Interaction between the Thwaites Ice Tongue and landfast sea ice}

The overall structural weakening of the Thwaites Glacier Tongue over the past two decades is likely to render it far more vulnerable to further retreat or disintegration in the near-future. For example, its present-day structure now strongly resembles Holmes Glacier in Porpoise Bay, (Figs 7a, b) which is reliant on multi-year landfast sea ice for structural integrity, and where sea-ice break-out events have been shown to trigger disintegration of large sections of its floating ice tongue (Fig. 7a; Miles and others, 2017). Elsewhere, the mechanical binding of landfast sea ice to the Mertz Glacier tongue has been shown to be important for the ice tongue's integrity (Massom and others, 2015). Given that the western margin of the Thwaites Glacier Tongue is also fastened to a band of multi-year sea ice, we hypothesise that the recently weakened Thwaites Glacier Tongue may now also have some dependency on landfast sea ice for structural integrity. The implication is that future break-outs of multi-year sea ice in front of the Thwaites Glacier Tongue could result in further structural weakening or even disintegration. This is supported by observations of the initiation of a partial break-out of multiyear sea ice in February 2019, which has resulted in the disintegration of a small section of the Thwaites Glacier Tongue on the western margin (Fig. 7b). Taken together, this means that the Thwaites Glacier Tongue would become more vulnerable to disintegration if landfast sea ice or pack ice were to become less persistent in the future.

Landfast sea ice is sensitive to changes in the ocean-climate system (Mahoney and others, 2007; Fraser and others, 2012). Individual break-out events can be driven by extreme climatic events (Fraser and others, 2012; Aoki and others, 2017; Miles and others, 2017), but abrupt changes can also be caused by changes in the local ice-scape (e.g. Tamura and others, 2012; 

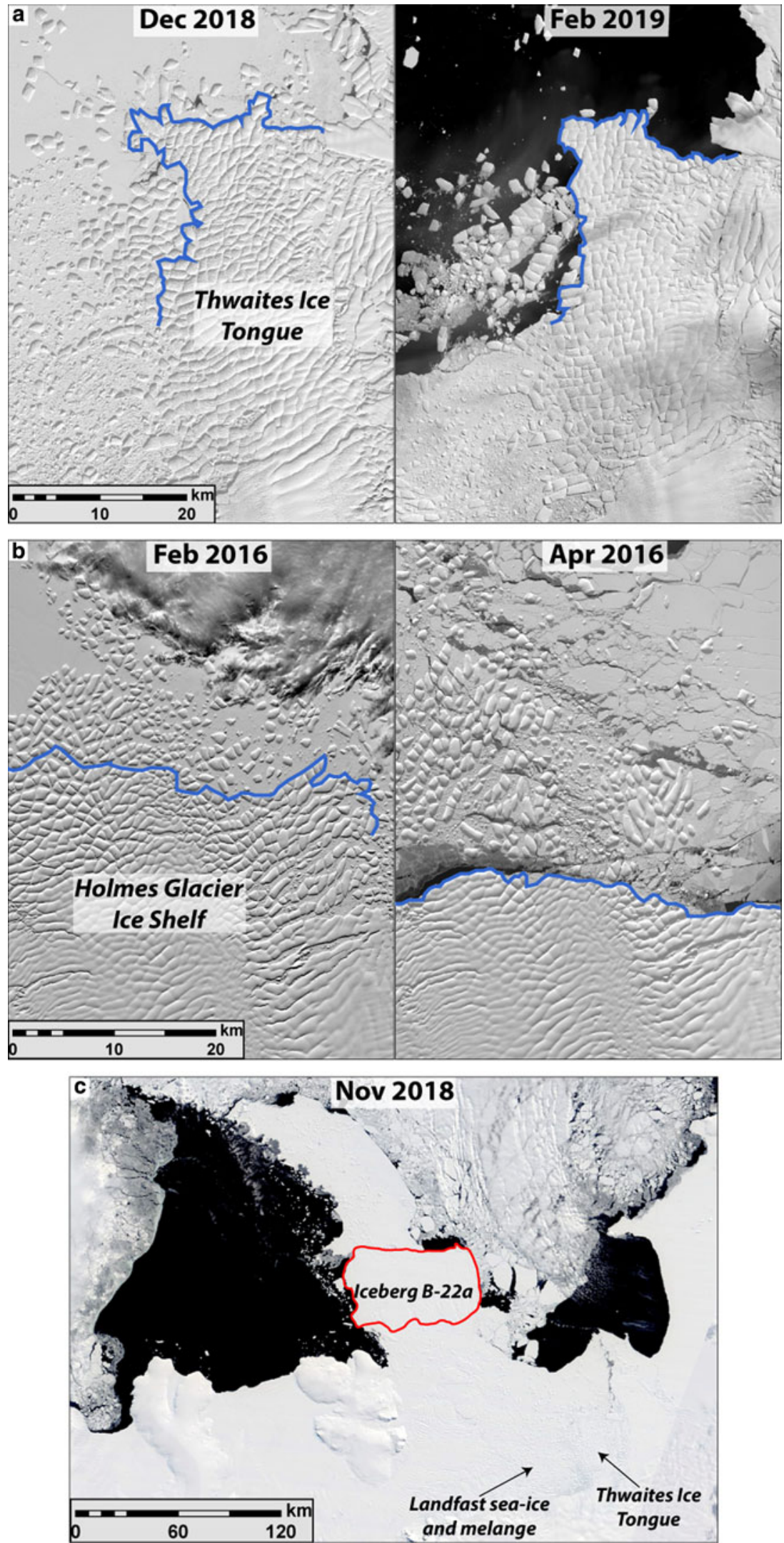

Fig. 7. Landsat-8 images of Thwaites Glacier Tongue (a) and Holmes Glacier, Porpoise Bay, East Antarctica (b). Note their similarities and structure. Holmes Glacier disintegrates during landfast sea-ice breakout events (e.g. Miles and others, 2017). A small portion of the Thwaites Glacier Tongue has disintegrated in response to a partial landfast sea-ice breakout. Ice-fronts are digitised in blue. (c) A MODIS image of the Amundsen Sea embayment. Note the grounded B-22A iceberg (digitised in red) and the dense landfast sea ice which is anchored on to it.

Massom and others, 2013; Campagne and others, 2015). An important component of the local sea-ice regime in the Thwaites embayment is the grounded B-22a iceberg (e.g. Stammerjohn and others, 2015), which lies $\sim 130 \mathrm{~km}$ out to sea north-east of Thwaites Glacier (Fig. 7c). Several studies have highlighted the importance of grounded icebergs or ice tongues (e.g. Mertz) acting as 'anchors', which help to facilitate growth and stabilise landfast sea-ice regimes (e.g. Massom and others, 2013; Fraser and others, 2012; Stammerjohn and others, 2015). Notably, the band of multi-year landfast sea ice attached to the western margin of the Thwaites Glacier Tongue is also anchored to the B-22a iceberg, suggesting that the iceberg is likely aiding the stability of the landfast sea ice (Fig. 7c). Therefore, when the grounded iceberg is removed from the Thwaites embayment 
(likely in the near-future), a change to less favourable landfast sea-ice conditions is likely to occur. Any decrease in landfast sea-ice persistency or extent would ultimately increase the prospect of further retreat or disintegration of the Thwaites Ice Tongue. This is important because while the tongue may only be providing a small amount of buttressing through its interaction with the Eastern Ice Shelf, it still acts as an important buffer for the inner ice shelf, by limiting potential damage from ocean waves and swell (e.g. Massom and others, 2018). Moreover, changes in either the ice tongue or landfast sea-ice extent could also have important implications on regional ocean circulation, with potential implications for melt rates at the GL (e.g. Webber and others, 2017).

\section{Summary}

Over the last 18 years, Thwaites Glacier Tongue has retreated $>80 \mathrm{~km}$, accelerated by $38 \%$ and has transitioned from a structurally-intact ice tongue capable of producing large tabular icebergs, to a mélange of smaller fractured icebergs bounded by sea ice. However, the rate of change throughout the observational period has not been uniform and we identify two distinct acceleration phases, separated by a period of deceleration. The largest acceleration took place between 2006 and 2012 when there was extensive structural weakening of the ice tongue and shear margins, along with a $23 \%$ increase in ice speed. However, between 2012 and 2015 there was a $6 \%$ slowdown in ice flow on the main Thwaites Glacier trunk, and there was a partial recoupling in flow between the Thwaites Glacier Tongue and the Eastern Ice Shelf as the structurally intact shear margin boundary advanced. The most recent acceleration started in January 2016 and is characterised by a major weakening of the eastern shear margin, which initiated on the ice tongue and, over the following months, propagated towards the GL as velocity gradients increased. The timing of the first acceleration coincides with a period of relatively warm ocean conditions, while relatively cool ocean conditions coincide with the deceleration phase. This correlation suggests that the ocean may be acting as a trigger for these distinct episodes of glacier behaviour.

Despite the major structural weakening of the Thwaites Glacier Tongue it may still be playing an import role in ice dynamics at the GL, meaning future changes in its extent are still an important consideration. As a result of the structural weakening over the past 18 years the Thwaites Ice Tongue now has some dependency on landfast sea ice for structural integrity. The removal of iceberg B-22a from the Thwaites embayment could result in a regime change, in that a reduction in the persistency of landfast sea ice would have detrimental impacts on the ice tongue's future structural integrity. There is a need for these complex processes associated with weakening ice tongues to be explored quantitatively through numerical modelling because they may have important implications for the rates of future sea level contributions.

Supplementary material. The supplementary material for this article can be found at https://doi.org/10.1017/jog.2020.20.

Acknowledgements. This work was funded by the Natural Environment Research Council (grant number: NE/R000824/1). MODIS imagery from the NASA WorldView Explorer is available at https://worldview.earthdata.nasa. gov/. Sentinel-1 imagery is available from the Copernicus Open Access Hub (https://scihub.copernicus.eu/). Landsat imagery is freely available and can be downloaded via Earth Explorer (https://earthexplorer.usgs.gov/). ESA SNAP software can be freely downloaded at http://step.esa.int/main/download/. GoLive Landsat-8 velocities are available at https://doi.org/10.7265/ N5ZP442B. Amundsen Sea velocities from 2000 and 2002 are available at https://oi.org/10.5067/MEASURES/CRYOSPHERE/nsidc-0545.001. MEaSUREs annual ice velocity maps are available at https://doi.org/10.5067/
9T4EPQXTJYW9. Grounding lines data are available at https:/doi.org/10.5067/ IKBWW4RYHF1Q. Ice-front positions collected in this study will be deposited in the NERC polar observation data centre upon publication. Velocity time series are available as a supplementary dataset. We would like to thank two anonymous reviewers and the editor - Helen Amanda Fricker - for providing constructive comments which led to the improvement of this manuscript.

\section{References}

Aoki S (2017) Breakup of land-fast sea ice in Lutzow-Holm Bay, East Antarctica, and its teleconnection to tropical Pacific sea surface temperatures. Geophysical Research Letters 44(7), 3219-3227.

Benn DI, Warren CR and Mottram RH (2007) Calving processes and the dynamics of calving glaciers. Earth-Science Reviews 82(3-4), 143-179.

Campagne $\mathbf{P}$ and others (2015) Glacial ice and atmospheric forcing on the Mertz Glacier Polynya over the past 250 years. Nature Communications 6. doi: $10.1038 /$ ncomms7642.

DeConto RM and Pollard D (2016) Contribution of Antarctica to past and future sea-level rise. Nature 531(7596), 591-+.

Dutrieux P and 9 others (2014) Strong sensitivity of Pine Island ice-shelf melting to climatic variability. Science (New York, N.Y.) 343(6167), 174-178.

Edwards TL, Brandon MA, Durand G, et al. (2019) Revisiting Antarctic ice loss due to marine ice-cliff instability. Nature 566, 58-64.

Fahnestock $\mathbf{M}$ and 5 others (2016) Rapid large-area mapping of ice flow using Landsat 8. Remote Sensing of Environment 185, 84-94.

Fraser AD, Massom RA, Michael KJ, Galton-Fenzi BK and Lieser JL (2012) East Antarctic Landfast sea ice distribution and variability, 2000-08. Journal of Climate 25(4), 1137-1156.

Fretwell P and others (2013) Bedmap2: improved ice bed, surface and thickness datasets for Antarctica. Cryosphere 7(1), 375-393.

Furst JJ and 6 others (2016) The safety band of Antarctic ice shelves. Nature Climate Change 6, 479-482.

Golledge NR and 5 others (2015) The multi-millennial Antarctic commitment to future sea-level rise. Nature 526(7573), 421-+.

Gudmundsson GH (2013) Ice-shelf buttressing and the stability of marine ice sheets. Cryosphere 7(2), 647-655. doi: 10.5194/tc-7-647-2013

Gudmundsson GH, Krug J, Durand G, Favier L and Gagliardini O (2012) The stability of grounding lines on retrograde slopes. Cryosphere 6(6), 1497-1505. doi: 10.5194/tc-6-1497-2012.

Gudmundsson GH, Paolo FS, Adusumilli S and Fricker HA (2019) Instantaneous Antarctic ice- sheet mass loss driven by thinning ice shelves. Geophysical Research Letters 46, 13903-13909.

Holt JW and 8 others (2006) New boundary conditions for the West Antarctic Ice Sheet: Subglacial topography of the Thwaites and Smith glacier catchments. Geophysical Research Letters 33, L09502. doi: 10.1029/2005GL025561.

Jacobs S and 5 others (2013) Getz ice shelf melting response to changes in ocean forcing. Journal of Geophysical Research: Oceans 118(9), 4152-4168.

Jenkins A and 6 others (2010) Observations beneath Pine Island Glacier in West Antarctica and implications for its retreat. Nature Geoscience 3(7), 468-472.

Jenkins A and 6 others (2016) Decadal ocean forcing and Antarctic ice sheet response: lessons from the Amundsen Sea. Oceanography 29(4), 106-117. doi: 10.5670/oceanog.2016.103.

Jenkins A and 7 others (2018) West Antarctic Ice Sheet retreat in the Amundsen Sea driven by decadal oceanic variability. Nature Geoscience 11(10), 733-+.

Joughin I, Smith BE and Medley B (2014) Marine ice sheet collapse potentially under way for the Thwaites Glacier Basin, West Antarctica. Science (New York, N.Y.) 344(6185), 735-738.

Konrad $\mathbf{H}$ and 6 others (2018) Net retreat of Antarctic glacier grounding lines. Nature Geoscience 11(4), 258-+

Lemos A and 5 others (2018) Ice velocity of Jakobshavn Isbr ae, Petermann Glacier, Nioghalvfjerdsfjorden, and Zacharias Isstrom, 2015-2017, from Sentinel 1-a/b SAR imagery. Cryosphere 12(6), 2087-2097.

MacGregor JA, Catania GA, Markowski MS and Andrews AG (2012) Widespread rifting and retreat of ice-shelf margins in the eastern Amundsen Sea Embayment between 1972 and 2011. Journal of Glaciology 58(209), 458-466.

Mahoney A, Eicken H, Gaylord AG and Shapiro L (2007) Alaska Landfast sea ice: links with bathymetry and atmospheric circulation. Geophysical Research Letters 112(C2). doi: 10.1029/2006JC003559. 
Massom R and 5 others (2013) Change and variability in East Antarctic Sea Ice Seasonality, 1979/80-2009/10. PLoS ONE 8(5). doi: 10.1371/journal. pone. 0064756

Massom RA and 7 others (2015) External influences on the Mertz Glacier Tongue (East Antarctica) in the decade leading up to its calving in 2010 Journal of Geophysical Research-Earth Surface 120, 490-506.

Massom RA and 5 others (2018) Antarctic ice shelf disintegration triggered by sea ice loss and ocean swell. Nature 558(7710), 383-+.

McMillan M and 7 others (2014) Increased ice losses from Antarctica detected by CryoSat-2. Geophysical Research Letters 41(11), 3899-3905.

Mercer JH (1978) West Antarctic ice sheet and $\mathrm{CO}_{2}$ greenhouse effect - threat of disaster. Nature 271(5643), 321-325.

Miles BWJ, Stokes CR and Jamieson SSR (2016) Pan-ice-sheet glacier terminus change in East Antarctica reveals sensitivity of Wilkes Land to sea-ice changes. Science Advances 2(5). doi: 10.1126/sciadv.1501350.

Miles BWJ, Stokes CR and Jamieson SSR (2017) Simultaneous disintegration of outlet glaciers in Porpoise Bay (Wilkes Land), East Antarctica, driven by sea ice break-up. The Cryosphere 11(1), 427-442.

Milillo P and 6 others (2019) Heterogeneous retreat and ice melt of Thwaites Glacier, West Antarctica. Science Advances 5(1). doi: 10.1126/sciadv.aau3433.

Millan R, Rignot E, Bernier V, Morlighem M and Dutrieux P (2017) Bathymetry of the Amundsen Sea Embayment sector of West Antarctica from operation ice bridge gravity and other data. Geophysical Research Letters 44(3), 1360-1368.

Moon T and Joughin I (2008) Changes in ice front position on Greenland's outlet glaciers from 1992 to 2007. Journal of Geophysical Research-Earth 113(F2). doi: 10.1029/2007JF000927.

Mouginot J, Rignot E and Scheuchl B (2014) Sustained increase in ice discharge from the Amundsen sea embayment, West Antarctica, from 1973 to 2013. Geophysical Research Letters 41(5), 1576-1584.

Mouginot J, Rignot E, Scheuchl B and Millan R (2017) Comprehensive annual ice sheet velocity mapping using Landsat-8, Sentinel-1, and RADARSAT-2 data. Remote Sens-Basel 9(4). doi: 10.3390/rs9040364.

Nicolas JP and others (2017) January 2016 Extensive summer melt in West Antarctica favoured by strong El Niño. Nature Communications 8, 15799.

Paolo FS, Fricker HA and Padman L (2015) Volume loss from Antarctic ice shelves is accelerating. Science (New York, N.Y.) 348(6232), 327-331.

Rignot E (2006) Changes in ice dynamics and mass balance of the Antarctic ice sheet. Philosophical Transactions of the Royal Society a-Mathematical Physical and Engineering Sciences 364(1844), 1637-1655.

Rignot E and 5 others (2019) Four decades of Antarctic Ice Sheet mass balance from 1979-2017. Proceedings of the National Academy of Sciences 116(4), 1095-1103.
Rignot E and MacAyeal D (1998) Ice-shelf dynamics near the front of the Filchner - Ronne ice shelf, Antarctica, revealed by SAR interferometry. Journal of Glaciology 44(147), 405-418.

Rignot E, Mouginot J, Morlighem M, Seroussi H and Scheuchl B (2014) Widespread, rapid grounding line retreat of Pine Island, Thwaites, Smith, and Kohler glaciers, West Antarctica, from 1992 to 2011. Geophysical Research Letters 41, 3502-3509.

Rignot E, Mouginot J and Scheuchl B (2011a) Antarctic grounding line mapping from differential satellite radar interferometry. Geophysical Research Letters 38. doi: 10.1029/2011GL047109.

Rignot E, Mouginot J and Scheuchl B $(2011 b)$ Ice flow of the Antarctic Ice Sheet. Science (New York, N.Y.) 333(6048), 1427-1430.

Sanderson T (1979) Equilibrium profile of ice shelves. Journal of Glaciology 22(88), 435-460. doi: 10.3189/S0022143000014453.

Scambos TA and others (2017) How much, how fast?: A science review and outlook for research on the instability of Antarctica's Thwaites Glacier in the 21st century. Global Planet Change 153, 16-34.

Scambos TA, Bohlander JA, Shuman CA and Skvarca P (2004) Glacier acceleration and thinning after ice shelf collapse in the Larsen B embayment, Antarctica. Geophysical Research Letters 31(18). doi: 10.1029/ 2004 GL020670.

Schoof C (2007) Ice sheet grounding line dynamics: steady states, stability, and hysteresis. Journal of Geophysical Research-Earth 112(F3).

Seroussi H and 6 others (2017) Continued retreat of Thwaites Glacier, West Antarctica, controlled by bed topography and ocean circulation. Geophysical Research Letters 44(12), 6191-6199.

Shepherd A and others (2018) Mass balance of the Antarctic Ice Sheet from 1992 to 2017. Nature 558(7709), 219-+.

Stammerjohn SE and 9 others (2015) Seasonal sea ice changes in the Amundsen Sea, Antarctica, over the period of 1979-2014. Elementa: Science of the Anthropocene 3. doi: 10.12952/journal.elementa.000055.

Tamura T, Williams GD, Fraser AD and Ohshima KI (2012) Potential regime shift in decreased sea ice production after the Mertz Glacier calving. Nature Communications 3. doi: 10.1038/ncomms1820.

Thoma M, Jenkins A, Holland D and Jacobs S (2008) Modelling circumpolar deep water intrusions on the Amundsen Sea continental shelf, Antarctica. Geophysical Research Letters 35(18). doi: 10.1029/2008GL034939.

Tinto KJ and Bell RE (2011) Progressive unpinning of Thwaites Glacier from newly identified offshore ridge: constraints from aerogravity. Geophysical Research Letters 38. doi: 10.1029/2011GL049026.

Webber BGM and 9 others (2017) Mechanisms driving variability in the ocean forcing of Pine Island Glacier. Nature Communications 8. doi: $10.1038 /$ ncomms 14507 . 